\title{
Study on Labor Cost Management Efficiency Using TOPSIS: Evidence from Hebei Southern Power Grid
}

\author{
Lei Wen ${ }^{1,2, a,{ }^{*},}$ Jian-Feng Weng ${ }^{1, b}$ \\ ${ }^{1}$ Department of Economics and Management, North China Electric Power University, Baoding, \\ Hebei 071003, China \\ ${ }^{2}$ The Academy of Baoding Low-Carbon Development, Baoding, Hebei 071003, China \\ a441477582@qq.com, bwenlei0312@126.com \\ ${ }^{*}$ Corresponding author
}

Keywords: Hebei southern power grid, Labor cost management, TOPSIS approach.

\begin{abstract}
Labor cost management and establishment of labor cost input-output efficiency system of subsidiaries are crucial for taking countermeasures against compatibility between salary growth of employees and enterprise's efficiency. An empirical research on labor cost management towards Hebei Southern Power Grid (subsidiary of State Grid) is then conducted via TOPSIS approach to implement annual performance review of ten subsidiaries. This study decomposes labor cost index system into eight indexes from perspective of static index and dynamic, then integrates the management of recruitment, compensation and relevant expenses, and simultaneously analyses the adaptability of labor cost variation trend and development level. Eventually, several scientific conclusions from the analysis are proposed, including the labor cost management rank of ten subsidiaries respectively and relevant incentives and disincentives.
\end{abstract}

\section{Introduction}

Overwhelming evidence indicates that research on labor cost management has been at the vanguard of attention for international and national enterprise efficiency. Despite fairly mature international study of labor cost management since R.OWEN, China has exerted continuous effort to develop theory of labor cost management, meanwhile experience multiple study objects, from simple salary to a combination of salary and bonus, later staff motivation etc. Hence, an enormous study potential in labor cost management needs to move on.

Hebei Southern Power Grid (hereafter referred to as HSPG), shoulders power responsibility across ten cities owning 15,800 square kilometers and 10,500,000 people. With the grid of $35 \mathrm{kV}$ substations 152 and power transmission capacity of 10.71 million $\mathrm{KV}$, gross electricity sales reach 15.236 billion $\mathrm{kwh}$, accounting for year-on-year growth of $2.86 \%$ at the top of performance appraisal comprehensive rankings in provincial grid company. Currently, HSPG has achieved the goal of monitoring of total amount, structure optimization and improvement of efficiency due to the overall manufacturing regulation rigidly and the universal PDCA system, i.e. accounting system, budgeting system, efficiency warning system and outcome assessment system[1-2].

Labor cost management is critical for the compatibility between salary growth and enterprise's efficiency, meanwhile the regulation of enterprise behaviors of income distributions to guarantee scientific development [3-4]. In this context, this paper takes a further note of the sound labor cost system of regulation under the empirical observation of subsidiaries, which is linked with the requirement of State Grid and combined with the management pattern of HSPG. Section 2 provides an overview of the main modeling process of TOPSIS method logically. Continuously, section 3 discusses performance evaluation of HSPG using TOPSIS approach, including yearly index system, data processing, rewards and punishments. Eventually, this paper concludes with a discussion of policy recommendations that derived from conclusions and discussions in section 4.

\section{Methodology}

This paper presents a specific application of TOPSIS method in labor cost performance measurement, which has more advantages in multi-objective-decision-making. Based on, TOPSIS 
serves to obtain optimal and worst schemes respectively represented by optimal and worst vectors, then calculate the distance of evaluation objects from optimal and worst schemes. Subsequently, figure out relevant closeness from evaluation objects to optimal and worst schemes, regarding it as the base of assessment [5]. The modeling process is proposed as below.

Firstly, the translation of decision-making matrix A into normalized decision-making matrix $\mathrm{Z}$. The elements of $\mathrm{Z}$ is calculated as $\mathrm{Z}_{\mathrm{ij}}$.

$$
z_{\mathrm{ij}}^{\prime}=\frac{f_{i j}}{\sqrt{\sum_{i=1}^{n} f_{i j}^{2}} \quad \mathrm{i}=1,2, \ldots, \mathrm{n} ; \mathrm{j}=1,2, \ldots, \mathrm{m}}
$$

where $\mathrm{f}_{\mathrm{ij}}$ is obtained from $\mathrm{A}$.

$$
\mathrm{A}=\left[\begin{array}{cccc}
\mathrm{f}_{11} & \mathrm{f}_{12} & \cdots & f_{1 m} \\
f_{21} & f_{22} & \cdots & f_{2 m} \\
\vdots & \vdots & \cdots & \vdots \\
f_{n 1} & f_{n 2} & \cdots & f_{n m}
\end{array}\right]
$$

Secondly, construction of the normalized and weighted decision-making matrix. The element of $\mathrm{Z}$ is calculated as $\mathrm{Z}_{\mathrm{ij}}$, where $\mathrm{W}_{\mathrm{j}}$ is weight of object $\mathrm{j}$.

$$
Z_{\mathrm{ij}}=W_{\mathrm{j}} Z_{i j}^{\prime} \mathrm{i}=1,2, \ldots, \mathrm{n} ; \mathrm{j}=1,2, \ldots, \mathrm{m}
$$

Thirdly, the confirmation of ideal solution and negative ideal solution. The higher the Zij value, the better scheme will be.

$$
\begin{aligned}
& Z^{+}=\left(Z_{1}^{+}, Z_{2}^{+}, \cdots, Z_{m}^{+}\right)=\left\{\max _{i} Z_{i j} \mid j=1,2, \cdots, m\right\} \\
& Z^{-}=\left(Z_{1}^{-}, Z_{2}^{-}, \cdots, Z_{m}^{-}\right)=\left\{\min _{i} Z_{i j} \mid j=1,2, \cdots, m\right\}
\end{aligned}
$$

Fourthly, calculation of distance from all scheme to ideal point $\mathrm{S}^{+}$and negative ideal point $\mathrm{S}_{\mathrm{i}}^{-}$

$$
\begin{aligned}
& S_{i}^{+}=\sqrt{\sum_{j=1}^{m}\left(Z_{i j}-Z_{j}^{+}\right)^{2}} \quad \mathrm{i}=1,2, \ldots, \mathrm{n} \\
& S_{i}^{-}=\sqrt{\sum_{j=1}^{m}\left(Z_{i j}-Z_{j}^{-}\right)^{2}} \\
& \mathrm{i}=1,2, \ldots, \mathrm{n}
\end{aligned}
$$

Eventually, finding satisfied solution based on the relevant closeness $C_{i}$ sorted by size [6].

$$
C_{i}=\frac{S_{i}^{-}}{S_{i}^{-}+S_{i}^{+}} \quad 0 \leq \mathrm{Ci} \leq 1, \mathrm{i}=1,2, \ldots, \mathrm{n}
$$




\section{Empirical analysis on performance evaluation}

\section{Annual index system}

From perspective of static and dynamic index, this paper decomposes annual index system into three dimensions and eight points to perform labor cost diagnosis. Table 1 describes the decomposition of annual index system. Table 2 illustrates detailed numerical value about overall indexes. Besides, percentage changes with 2012 as the base year. $S_{n}$ indicates subsidiary $n$.

Tab.1 Decomposition of yearly labor cost management index system

\begin{tabular}{cccc}
\hline & $\begin{array}{c}\text { First class } \\
\text { indexes }\end{array}$ & Second class indexes & \\
& & Average labor cost $\left(10^{4}\right.$ yuan/per $)$ & $\mathrm{C} 1$ \\
& & Business households $\left(10^{4}\right.$ households $)$ & $\mathrm{C} 2$ \\
& Gross electricity sales $\left(10^{4} \mathrm{KHW}\right)$ & $\mathrm{C} 3$ \\
& Static index & Average electricity sales $\left(10^{4} \mathrm{KHW}\right)$ & $\mathrm{C} 4$ \\
Labor & Ratio of total wages to total cost $(\%)$ & $\mathrm{C} 5$ \\
cost & Rate of labor allocation $(\%)$ & $\mathrm{C} 6$ \\
managem & Rate of personal costs $(\%)$ & $\mathrm{C} 7$ \\
ent index & & Ratio of labor cost to total cost $(\%)$ & $\mathrm{C} 8$ \\
system & & Growth rate of average labor cost $(\%)$ & $\mathrm{C} 10$ \\
& & Growth rate of business households $(\%)$ & $\mathrm{C} 11$ \\
& Dynamic & Growth rate of gross electricity sales $(\%)$ & $\mathrm{C} 12$ \\
& index & Growth rate in ratio of total wages to total cost & $\mathrm{C} 13$ \\
& & Growth rate of labor allocation rate $(\%)$ & $\mathrm{C} 14$ \\
& & Growth rate of personal costs rate $(\%)$ & $\mathrm{C} 15$ \\
& & Growth rate in ratio of labor cost to total cost $(\%)$ & $\mathrm{C} 16$ \\
\hline
\end{tabular}

Tab.2 Index value of labor cost management in HSPG yearly

\begin{tabular}{ccccccccccc}
\hline & S1 & S2 & S3 & S4 & S5 & S6 & S7 & S8 & S9 & S10 \\
\hline C6 & 5.72 & 3.04 & 3.23 & 6.71 & 4.21 & 6.55 & 6.35 & 4.82 & 4.56 & 2.87 \\
C14 & -0.03 & 0.04 & 0.02 & 0.04 & 0.01 & 0.04 & 0.02 & -0.05 & -0.06 & -0.04 \\
C7 & 5.36 & 2.91 & 3.08 & 6.45 & 4.05 & 6.19 & 5.71 & 4.59 & 4.29 & 2.78 \\
C15 & -0.08 & -0.03 & -0.04 & -0.01 & -0.06 & -0.03 & -0.04 & -0.08 & -0.12 & -0.09 \\
C8 & 28.95 & 32.68 & 29.8 & 32.6 & 30.86 & 31.95 & 22.96 & 32.76 & 27.56 & 35.25 \\
C16 & -0.19 & -0.17 & -0.19 & -0.3 & -0.29 & -0.22 & -0.23 & -0.08 & -0.23 & -0.16 \\
C1 & 6.9 & 7.5 & 7.4 & 6.8 & 7.2 & 7.2 & 7.1 & 6.9 & 6.9 & 7.7 \\
C9 & -0.01 & 0.01 & 0.01 & 0 & 0 & 0.01 & 0 & 0 & -0.03 & 0.01 \\
C5 & 0.63 & 0.63 & 0.62 & 0.62 & 0.61 & 0.62 & 0.62 & 0.62 & 0.63 & 0.62 \\
C13 & 0.02 & 0.02 & -0.02 & 0 & -0.02 & 0 & 0 & -0.02 & 0.02 & 0 \\
C2 & 26561 & 39812 & 28402 & 11875 & 18335 & 15841 & 34608 & 18027 & 25167 & 18304 \\
C10 & 0.01 & 0.01 & 0.01 & 0.01 & 0.01 & 0.01 & 0.01 & 0.01 & 0.01 & 0.01 \\
C3 & 15509.3 & 35216.3 & 28722.5 & 9614.5 & 18910.6 & 16478.0 & 12422.8 & 14883.8 & 15518.3 & 30761.9 \\
C11 & 0.05 & 0.05 & 0.05 & 0.05 & 0.05 & 0.05 & 0.05 & 0.05 & 0.05 & 0.05 \\
C4 & 128.22 & 219.23 & 204.93 & 92.73 & 166 & 137.68 & 119.82 & 119.26 & 126.29 & 234.47 \\
C12 & 0.05 & 0.05 & 0.05 & 0.05 & 0.05 & 0.05 & 0.05 & 0.05 & 0.05 & 0.05 \\
\hline
\end{tabular}

\section{Data processing and empirical study}

Among all the original index value, low-optimization index incorporates rate of labor allocation, 
rate of personal costs, ratio of labor cost to total cost, ratio of total wages to total cost, average labor cost and their growth rate, namely the lower the better for index value[7]. Furthermore, high-optimization index involves in business households, gross electricity sales, average labor cost and their growth rate, namely the higher the better for index value [8]. In general, low-optimization index x can be inverted into high-optimization index using inverse method, namely 100/x[9], while relative low-optimization index $\mathrm{x}$ instead of differential method, namely $(1-\mathrm{x})$.

Subsequently, normalized decision-making matrix $\mathrm{Z}$ is obtained based on Eq. (1). For example, rate of labor allocation in $\mathrm{S} 1$ adhere $\mathrm{s}$ to the following equation.

$$
\mathrm{Z}_{11}=\frac{0.94}{\sqrt{0.94^{2}+0.97^{2}+0.97^{2}+0.93^{2}+0.96^{2}+0.93^{2}+0.94^{2}+0.95^{2}+0.95^{2}+0.97^{2}}}
$$

By that analogy, remaining normalized values can be calculated, where $\mathrm{f}_{\mathrm{ij}}$ is derived from decision-making matrix A.

$$
\mathrm{A}=\left[\begin{array}{cccc}
0.10 & 0.10 & \cdots & f_{1 m} \\
0.11 & 0.11 & \cdots & f_{2 m} \\
\vdots & \vdots & \cdots & \vdots \\
f_{n 1} & f_{n 2} & \cdots & f_{n m}
\end{array}\right]
$$

In addition, ideal solution $\mathrm{Z}^{+}$and negative ideal solution $\mathrm{Z}^{-}$is confirmed by Eq. (4) and Eq. (5) respectively. The higher the $Z_{\mathrm{ij}}$ value, the better scheme will be.

$$
\begin{aligned}
& \mathrm{Z}^{+}=\left(\mathrm{Z}_{1}^{+}, \mathrm{Z}_{2}^{+}, \cdots, \mathrm{Z}_{\mathrm{m}}{ }^{+}\right) \\
& =\left(\begin{array}{llllllll}
0.11 & 0.11 & 0.16 & 0.75 & 0.06 & 0.06 & 0.08 & 0.09
\end{array}\right. \\
& \begin{array}{llllllll}
0.11 & 0.10 & 0.09 & 0.10 & 0.10 & 14.39 & 2.00 & 2.00)
\end{array} \\
& \mathrm{Z}^{-}=\left(\mathrm{Z}_{1}^{-}, \mathrm{Z}_{2}^{-}, \cdots, \mathrm{Z}_{\mathrm{m}}^{-}\right) \\
& =\left(\begin{array}{llllllll}
0.10 & 0.10 & 0.13 & 0.66 & 0.06 & 0.02 & 0.02 & 0.04
\end{array}\right. \\
& \begin{array}{llllllll}
0.10 & 0.09 & 0.07 & 0.10 & 0.10 & 14.21 & 2.00 & 2.00)
\end{array}
\end{aligned}
$$

Eventually, it is a key to calculate the distance from all scheme to ideal point $\mathrm{S}_{\mathrm{i}}{ }^{+}$and negative ideal point $\mathrm{S}_{\mathrm{i}}{ }^{-}$using Eq. (6) and Eq. (7), then discover the relevant closeness $\mathrm{C}_{\mathrm{i}}$ from feasible solution to ideal solution using Eq. (8). Meanwhile, the value of static index weight is set as 0.7 and dynamic index weight value equals 0.3 synthesizing all experts' opinion. Table 3 demonstrates the sorted results by relevant closeness $\mathrm{C}_{\mathrm{i}}$.

Tab.3 Sorted results by relevant closeness $\mathrm{Ci}$

\begin{tabular}{ccccc}
\hline & $\mathrm{S}_{\mathrm{i}}^{+}$ & $\mathrm{S}_{\mathrm{i}}^{-}$ & $\mathrm{C}_{\mathrm{i}}$ & Order \\
\hline $\mathrm{S} 1$ & 0.07 & 0.09 & 0.58 & 9 \\
$\mathrm{~S} 2$ & 0.09 & 0.08 & 0.48 & 6 \\
$\mathrm{~S} 3$ & 0.11 & 0.06 & 0.34 & 1 \\
$\mathrm{~S} 4$ & 0.11 & 0.08 & 0.42 & 2 \\
S5 & 0.08 & 0.07 & 0.45 & 5 \\
S6 & 0.08 & 0.08 & 0.51 & 3 \\
S7 & 0.09 & 0.07 & 0.43 & 8 \\
S8 & 0.08 & 0.09 & 0.53 & 10 \\
S9 & 0.06 & 0.12 & 0.69 & 4 \\
S10 & 0.10 & 0.08 & 0.44 & \\
\hline
\end{tabular}

\section{Rewards and punishments}

In views of sorted results by relevant closeness $C_{i}$, HSPG take yearly performance appraisal of 
enterprise and total wages fluctuation at the beginning of budgetary total wages planning. In principle, feasible scheme is close to ideal solution with $C_{i}$ value approaching 1 . Namely, the higher $\mathrm{C}_{\mathrm{i}}$ value is, the higher labor cost will be. Hence, subsidiary with a lower $\mathrm{C}_{\mathrm{i}}$ value is top-ranked.

Rewards and punishments show that, S3, in the first place, obtains a reward about 10 point of performance appraisal of enterprise and an additional bonus of total wages increase by 3\%; while S9 being the last, is punished with a deducted 10 point for performance appraisal of enterprise and a reduction of total wages by $0.2 \%$. As for other rewarded subsidiaries, S4 being the second, S7 being the third and S10 being the fourth, receive the reward with performance appraisal of enterprise increasing by 5 points, 2 points, 1 point respectively and total wages increasing by $2 \%, 1 \%, 0.5 \%$ respectively. In case of common labor cost regulation, S5 enjoy average input-output efficiency without any incentive or penalty. In view of other punished subsidiaries, S2, S6, S8 and S1 being the sixth, seventh, eighth, ninth respectively, undergo the punishments with deducted 1 point, 2 points, 3 points, 5 points of enterprise performance appraisal and a reduction of total wages by $0.1 \%$, $0.2 \%, 0.3 \%, 0.5 \%$ separately.

\section{Conclusions and discussions}

For the sake of compatibility between enterprise efficiency and salary growth thus improving labor cost management efficiency, this paper attempts to provide new evidence using intuitionistic fuzzy sets, meanwhile employ effective steps, like monthly dynamic monitoring, ten subsidiaries ranking and corresponding rewards and punishments. The study concludes with below results.

(1) The trend of labor cost increasing substantially, especially contrastive analysis between 2013 and 2012, is attributed to majorities of intricate properties, like drastic growth in total wages, social insurance expenditure and welfare expenditure. More specifically, the upward trend in 2013 appears due to more persons, higher benchmark of social insurance expenditure, not less strength of investment in labor security, in view of per capita income balance.

(2) The indexes of rate of labor allocation, rate of personal cost, and ratio of labor cost to total cost in S8, S5, S4 and S6 appear to be above average level, accounting for $40 \%$ of overall subsidiaries. The priority for these subsidiaries is to put serious labor cost control ahead on the premise of profit-maximization, such as layoff to reduce labor costs and enhance labor cost efficiency.

(3) Based on a slight increase in labor cost, coefficients of per labor cost sales revenue from ten subsidiaries in 2013 are higher than the ones in 2012, indicating the more business revenue of per labor cost. Among that, the per output-coefficients of labor cost in S8, S9, S1 and S10 are higher than the ones in 2012, illustrating the increasing per output of labor cost. On the contrary, other subsidiaries perform a lower per output-coefficients of labor cost and a decreasing per output-coefficients.

(4) The remainder show that, the average labor productivity of all staff is 1711300 yuan with a upward trend of $0.43 \%$; the average per capita wage is 44700 yuan, increasing by $0.22 \%$; the ratio of labor productivity amplification to average wage amplification is $1.95: 1$, showing a reasonable wage growth rate to generate greater benefits.

\section{Policy recommendations}

Policy recommendations derived from above-mentioned conclusions are provided to mitigate labor cost management issues, more specifically summarized as below.

Firstly, there is a necessity to formulate thorough management instructions, including statistic analysis, process monitoring and performance appraisal. That is to say, improvement of labor cost data quality, effective budget and final accounts, monitoring and early warning, completion rates of planned objectives, also rewards and punishments are pivotal.

Secondly, reinforcement of organizational alignment and management effectiveness is exerted continuous efforts. Establishment of sound organization thus showing attentiveness of leaders to duties, is a response to strengthen internal management, including human resources department 
responsibilities, i.e. a better mutual communication among other departments, decomposition of budget in all departments, regular monitoring and warning; Moreover, other management departments duties in comply with the principle " Those who are in charge should perform their role". In addition, integration of labor cost management projects combining with the current condition is an initiative to realize the labor cost optimization of input-output ratio. Especially, projects like wage, basic insurance, supplemental insurance, and educational fund are under unified verification and management of human resources department to comprehensively utilize resources and deepening reform.

Thirdly, in order to orient toward performance appraisal and enhance awareness of labor cost regulation, bringing labor cost evaluation results into the yearly performance appraisal of leaders is crucial. From the perspective of improving input-output efficiency, subsidiaries in HSPG vigorously take countermeasures against the issue of a lower labor cost with a more benefits thus produce a benign input-output circulation-mechanism.

\section{Acknowledgment}

This work is supported by the Fundamental Research Funds for the Central Universities (No. 12ZX12).

\section{References}

[1] Ling Huang. The improvement study and practice exploration on labor cost theory [D].North China Electric Power University (Beijing), 2006.

[2] Zhiqiang $\mathrm{Hu}$. Study on the regulation of labor cost management in large and medium-sized state-owned enterprises [D]. Northwestern Polytechnical University, 2007.

[3] Yufeng Shi. Study on the model of cost management and regulation in electricity construction project [D]. North China Electric Power University, 2013.

[4] Juhong Cui. Talking to labor cost management of electricity construction enterprise [J]. Shandong electricity college journals. 2004, 02:23-25.

[5] Hui Hu,Zeshui Xu. Interval intuitionistic fuzzy multiple decision-making based on TOPSIS method [J]. Fuzzy Systems and Mathematics. 2007, 05:108-112.

[6] Guoqiang Yang. The theory of strengthening the awareness of labor cost management and reducing staff for greater efficiency $[\mathrm{J}]$. Journal of xi 'an petroleum institute (social science edition). 2000, 01:62-64.

[7] Shoukang Qin. The model of TOPSIS value function [J]. Journal of Systems Engineering. 2003, $01: 37-42$.

[8] Ludmila Dymova,Pavel Sevastjanov,Anna Tikhonenko. A direct interval extension of TOPSIS method [J]. Expert Systems with Applications, 2013, 4012.

[9] Ibrahim A. Baky. Interactive TOPSIS algorithms for solving multi-level non-linear multi-objective decision-making problems [J]. Applied Mathematical Modelling, 2013. 